\title{
АНАЛИЗ СУЩЕСТВУЮЩИХ МЕХАНИЗМОВ ПОДДЕРЖКИ ИНИЦИАТИВ НАСЕЛЕНИЯ В СФЕРЕ ПРЕДПРИНИМАТЕЛЬСТВА В РОССИИ *
}

\author{
(c) 2020 Толмачев Михаил Николаевич \\ доктор экономических наук, профессор департамента бизнес-аналитики \\ Финансовый университет при Правительстве РФ, Россия, Москва \\ E-mail:MNTolmachev@fa.ru \\ (C) 2020 Никифорова Елена Владимировна \\ доктор экономических наук, профессор департамента бизнес-аналитики \\ Финансовый университет при Правительстве РФ, Россия, Москва \\ E-mail:EVNikiforova@fa.ru
}

Анализ существующих механизмов поддержки инициатив населения в сфере предпринимательства в России обусловил актуальность определения новых сфер занятости и соответствующих профессий. Важность вопросов обеспечения диверсификации занятости населения в настоящее время очевидна не только для России, но и для рада зарубежных стран.

Развитие предпринимательских инициатив является весьма актуальным вопросом российского экономического пространства. Предпринимательство считается одним из основных факторов социально-экономического развития и ключевым условием для достижения конкурентоспособности экономики страны.

Возникновение новых направлений и видов деятельности способствует востребованности в новых профессиях и специальностях. Концепция развития экономики, ориентированная на внедрение новых направлений, дает возможность для социально-экономического рывка в сфере диверсификации занятости не только на уровне государства, но и мирового пространства в целом.

Однако необходимо отметить, что вызывает жаркие дискуссии ведущих специалистов в данной области оценка влияния четвертой промышленной революции и цифровой экономики. Ряд ученых обусловливают данное влияние как определённую закономерность очередного этапа процесса технологического развития. Другие утверждают, что кардинальное изменение экономики всех мировых стран в целом формируют цифровые технологии, как в прочем и быт населения любой страны.

Развитие предпринимательских инициатив является одной из актуальных проблем российского экономического пространства.

Для понимания стимулов, воздействующих на предпринимательскую активность, очень важно иметь некоторую информацию о ее общественном восприятии в тех условиях, в которых осуществляется предпринимательская деятельность. В представлении населения развитых стран предприниматель рассматривается как свободный нонконформист, способный идти на риск и мобилизовать людей и активы, необходимые для создания успешных коммерческих проектов. Важность вызовов предпринимательства имеет обособленный аспект, который варьируется в зависимости от регионального значения.

Ключевые слова: возможности, внутренний контроль, нарушения, процесс, система, федеральные проекты, финансы.

Происходящие технологические изменения повлекут за собой сокращение традиционной занятости. Актуальность определения новых сфер занятости и соответствующих профессий очевидна, как очевидно и то, что вопросы предпринимательства в современном обществе имеют свою экономическую окраску и занимают умы ведущих специалистов.

Вопросами формирования предпринимательской среды в трансформирующейся экономике и проблемами малого бизнеса занимаются современные ученые: В.А.Базжина [1, С. 71-86.], А. В.Виленский и др. [2, С. 153-167.], Е. С. Дашкова и Н.В.Дорохова [3], С. Кройтор [4, С. 136-154]. За-

\footnotetext{
* Исследование выполнено в рамках научного проекта ГПХ ВТК-ГЗ-ПИ-35-20 «Обеспечение диверсификации занятости и разработка механизмов поддержки инициатив населения в сфере предпринимательства»
} 
рубежная практика предпринимательской деятельности отражена в научных трудах: C. Degryse [9], M. Taylor [16], Stephen R. Barley, Beth A. Bechky, Frances J.Milliken [15] и т.д.

В научных кругах дискуссионность прослеживается и в понятийном аппарате дефиниции «диверсификация». Е. Е. Румянцевой диверсификация определяется, как «общая деловая практика, направленная на расширение номенклатуры товаров и услуг и (или) географической территории, для того, чтобы рас сосредоточить риск и снизить зависимость от циклического бизнеса» [6, c. 826].

Т.В.Усковой, С.С.Копасовой диверсификация рассматривается как «расширение видов экономической деятельности и вклад новых видов в социально-экономическое развитие региона с целью повышения конкурентоспособности и улучшения благосостояния населения» [7].

Диверсификация в зарубежной практике рассматривается как «процесс структурной трансформации экономики, который сопровождается смещением ресурсов из первичного сектора экономики во вторичный (обрабатывающий) и третичный (сервисный) сектора» [13].

Учитывая важность вопросов диверсификации занятости населения на международном уровне отметим, что наиболее эффективной считается социал-демократическая политика стран Северной Европы (Швеция, Дания) по расширению занятости в государственном секторе. Например, в конце XX века в этих странах начался процесс создания трудоемкой системы социальных услуг (особенно услуг по уходу за детьми и пожилыми людьми), что привело к увеличению предложения рабочей силы, совмещению родителями работы и семейной жизни и, в конечном итоге, к увеличению общего количества занятых [8].

Однако в настоящее время все постиндустриальные страны столкнулись с проблемой старения населения, что приводит к необходимости привлечения иностранной рабочей силы. Минусами активной трудовой миграционной политики являются высокие социальные и экономические издержки интеграции иностранного населения с различными культурными традициями и языками. Затраты на интеграцию особенно велики в случае низкоквалифицированных иностранных работников из менее развитых стран, которые не только создают нагрузку на бюджет и систему образования, но и вызывают социальные конфликты. В некоторых странах, таких как Канада, введена система объективных критериев оценки квалификации иностранной рабочей для выдачи разрешений на работу [14, С. 104-112.].

Предпринимательство считается одним из основных факторов социально-экономического развития и ключевым условием для достижения конкурентоспособности экономики страны. Малые и средние предприятия играют существенную роль в экономике и выполняют в ней важные функции, которые влияют на конкурентоспособность и стимулируют ее рост. К этим функциям относятся [10]:

a) влияние на функционирование рынка труда. Это влияние двояко: во-первых, предприниматели создают новые рабочие места для себя, своих семей и сотрудников, а во-вторых, они могут устанавливать и распространять стандарты рынка труда;

б) создание возможностей для более полного использования существующих ресурсов, что, соответственно, влияет на эффективность экономики. Это, в основном, относится к экономическим субъектам, которые не в состоянии создавать резервы и, следовательно, чтобы выжить и процветать в условиях конкурентной борьбы, должны максимально эффективно использовать ресурсы, находящиеся в их распоряжении;

в) создание оптимальных комбинаций факторов производства. Экономические субъекты, которые в полной мере используют свои ресурсы, стремятся к правильному сочетанию производственных факторов;

г) принятие на себя рисков, связанных с ведением бизнеса. Деятельность современных предприятий связана с постоянной неопределенностью, потому что ситуация на рынке не позволяет достаточно уверенно прогнозировать вероятность успеха предпринимаемых решений;

д) стимулирование локального развития и положительное влияние на окружающую среду. Деятельность даже одного предприятия может положительно влиять на местный социальноэкономический климат. Предприниматели не только обеспечивают занятость населения, но и стимулируют создание новых (аффилированных с ними) предприятий, что также влияет на экономическую активность местного населения;

е) предоставление льгот для инвесторов. 
Предприниматели, которые стремятся к развитию своего экономического субъекта, часто используют для этой цели средства инвесторов. С другой стороны, действия, стимулирующие развитие экономического субъекта, приносят выгоду инвесторам;

ж) формирование гибкости рынков. Предпринимательство является одним из самых важных механизмов регулирования рынка, потому что благодаря этому рынок может быстро реагировать даже на слабые сигналы спроса;

3) повышение гибкости организационных структур и стимулирование разработки современных организационных решений и инноваций в области управления;

и) положительное влияние на экономическое развитие. Формирование новых и развитие существующих предприятий ускоряет темпы развития национальной экономики. Новые предприятия, в первую очередь из категории малого и среднего бизнеса, играют особую роль, потому что они способствуют качественным изменениям структуре экономики.
Бесспорно, что содействие предпринимательским инициативам населения является одной их важных предпосылок к развитию экономики. По этому параметру Россия на фоне развитых зарубежных стран находится далеко не в первых рядах (рисунок 1).

Еще один важный показатель - доля малых и средних предприятий в ВВП страны. Здесь также высвечиваются проблемы функционирования малого бизнеса в России на фоне зарубежных стран (см. рисунок 2).

Проблемы в развитии этого сектора российской экономики достаточно очевидны. Одним из основных факторов, оказывающих влияние на распространенность предпринимательских инициатив, являются культурные особенности. Вопросы культуры находятся в фокусе любых дискуссий, связанных с предпринимательскими инициативами. Культурные особенности страны являются одним из наиболее важных факторов, который значимо влияет на степень инноваций и развития предпринимательских инициатив.

Отметим факт того, что различия в социаль-

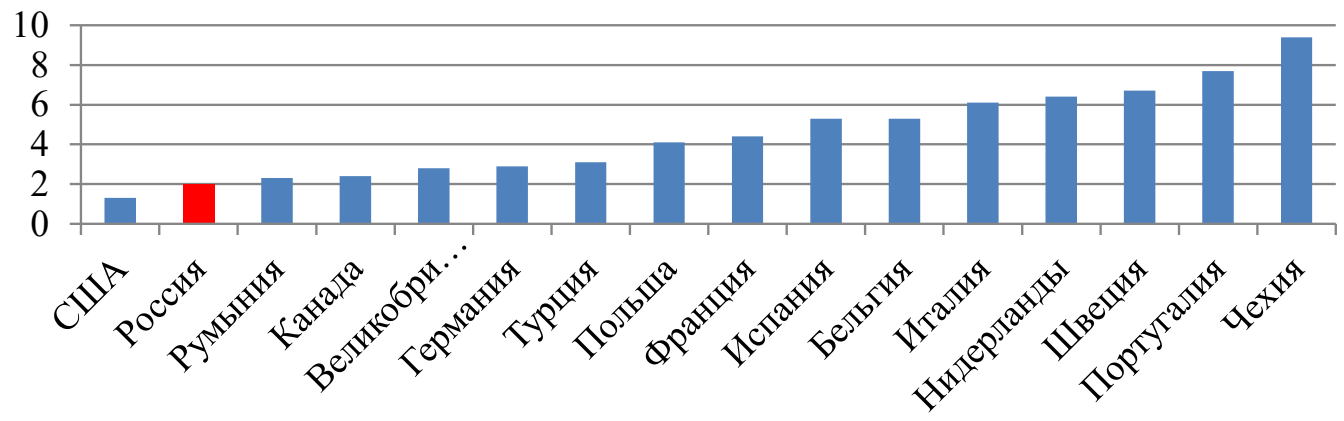

Рисунок 1. Количество малых и средних предприятий на 1000 человек населения, 2018 г. Источник: ОЭСР, ООН, ФНС России

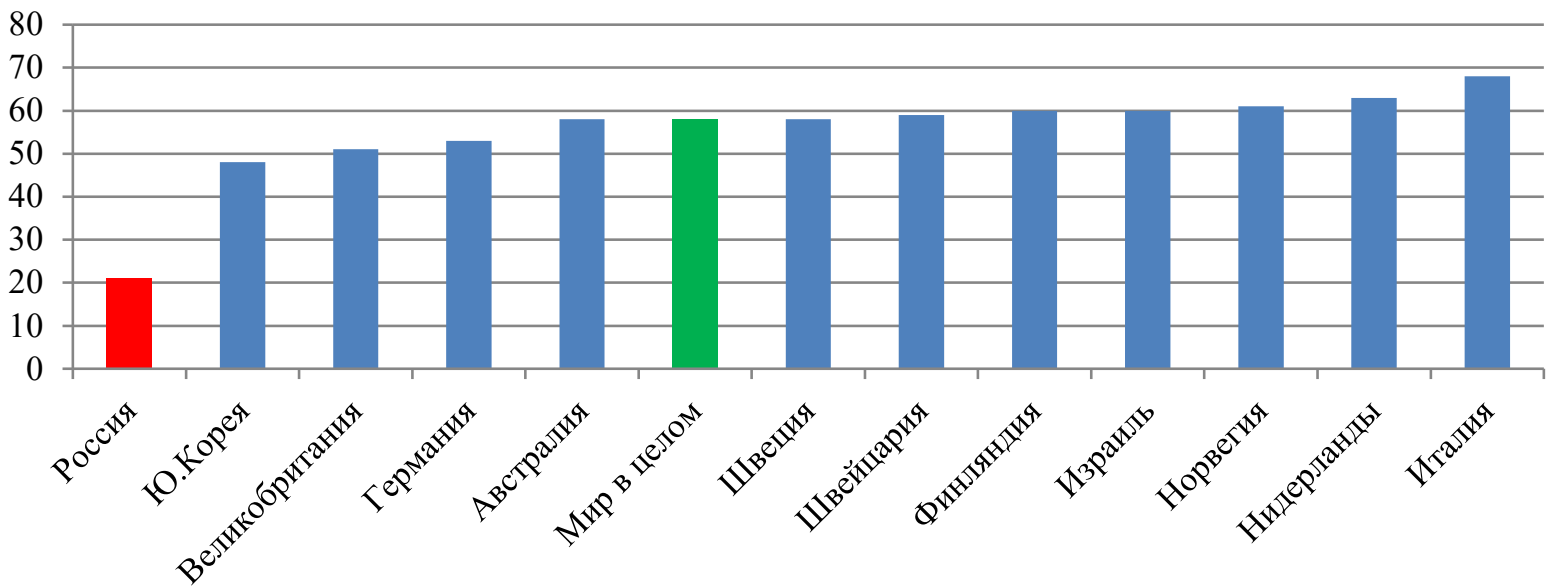

Рисунок 2. Удельный вес малых и средних предприятий в ВВП,\% Источник: Российская венчурная компания 
ных представлениях по отношению к предпринимателям могут значимо влиять на успешность ведения бизнеса в той или иной стране. В представлении населения развитых стран предприниматель рассматривается как свободный нонконформист. Для того, чтобы численность таких людей росла, должны соблюдаться, как минимум, два условия (см. рисунок 3).

Первое условие требует, чтобы предпринимательская деятельность одобрялась большей частью общества и воспринималась не просто как легальный, но как честный и уважаемый способ заработка.

Второе условие требует наличия социальных институтов и возможностей получения потенциальным предпринимателям доступ к основным активам. Этот фактор более подвержен регулированию со стороны государственных органов, однако степень доступности финансовых и иных ресурсов для осуществления предпринимательской деятельности, так или иначе, зависит от имиджа бизнеса в глазах населения и государственных структур.

Для российской экономики характерны следующие специфические черты:

а) сравнительно низкий уровень развития малого и среднего бизнеса, проявляющийся в их небольшом вкладе в ВВП, малом числе соответ- ствующих предприятий на 1000 человек населения, низкими средними показателями рентабельности и прибыли;

б) своеобразная структура по видам экономической деятельности, имеющая сильный перекос в сторону торговли и операций с недвижимостью. В развитых странах основная часть малых и средних предприятий работает в сфере торговли, услуг (в том числе информационных технологий) и общественного питания;

в) высокий уровень рисков, в первую очередь порождаемых высоким уровнем административно-коррупционной нагрузки со стороны государства. Большое число контролирующих органов, которые сами являются практически неподконтрольными, оказывают серьезное давление на бизнес, значительно повышая его издержки;

г) низкая платежеспособность населения (в первую очередь в регионах), что является серьезным барьером на пути к достижению уровня окупаемости малого бизнеса.

Учитывая высокую (и имеющую тенденцию к дальнейшему увеличению) долю государства в экономике России, одним из вариантов стимулирования предпринимательской активности может стать модель государственно-частного партнерства (ГЧП).

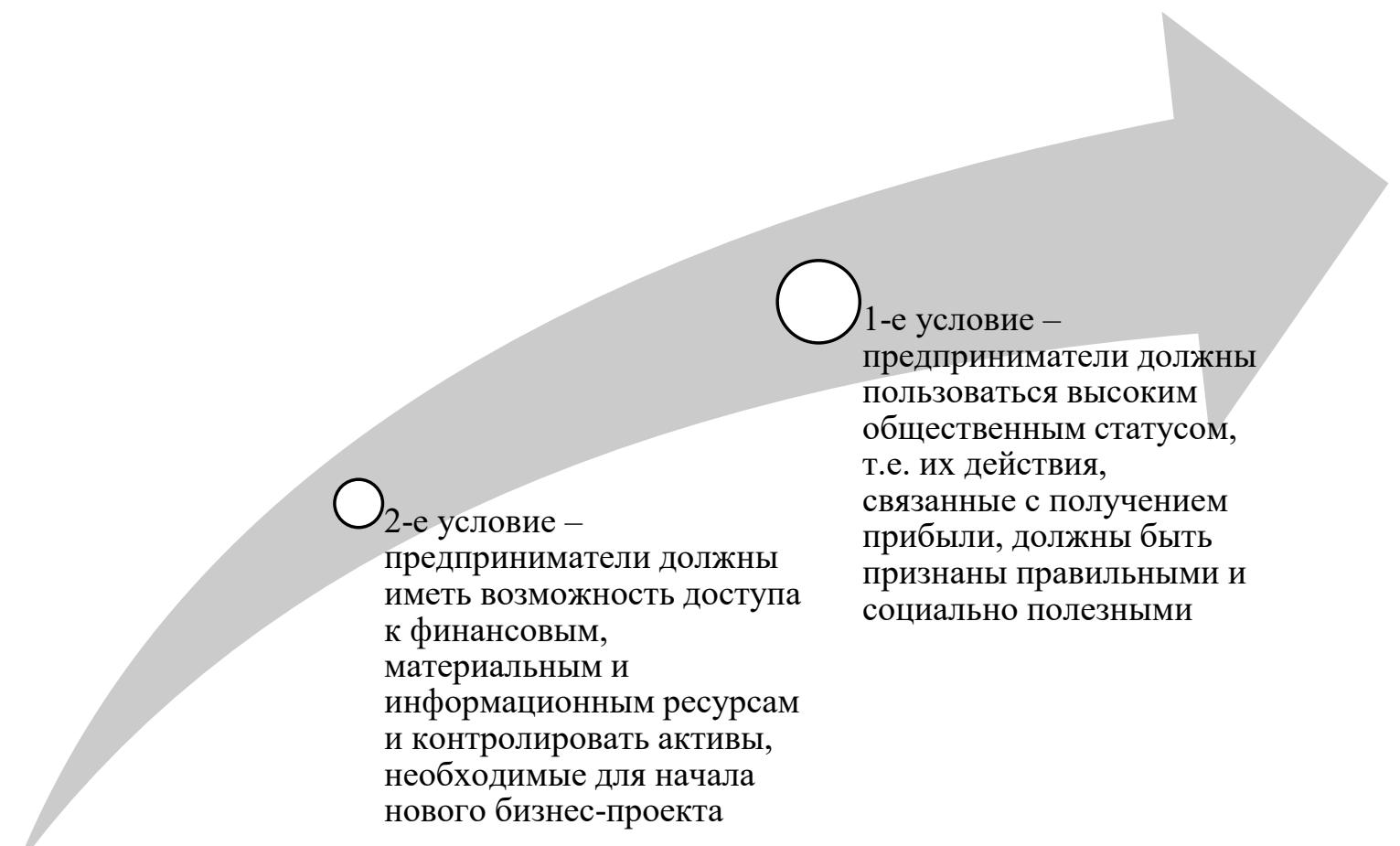

Рисунок 3. Условия роста предпринимательских инициатив 
Согласно определению, И. Мерзлова, государственно-частное партнерство - это «любая форма партнерства государства и частного бизнеса, в том числе государственный заказ, приватизация, концессия, аренда, вклады в уставный капитал государственных или частных компаний, приобретение долей государством в этих частных компаниях и т.д., нацеленная на создание, модернизацию и эксплуатацию объектов экономической и социальной инфраструктуры» [5, С. 83].

Исходя из выше изложенного, можно выделить конкретные меры поддержки инициатив населения со стороны государства в проекте ГЧП (см. рисунок 4).

Мерам поощрения предпринимательской активности со стороны финансовой системы считаются:

a) снижение объема банковских гарантий, необходимых для получения кредита;

б) дифференцированный подход к условиям кредитования в зависимости от вида экономической деятельности;

в) снижение процентных ставок по кредитам предпринимателям.

По нашему мнению, государство, в первую очередь, должно в большей степени развивать методы пассивной поддержки бизнеса. Это не только способствует экономии бюджетных средств, но и позволит значительно снизить коррупционные риски в данной области. Точечная, адресная поддержка предпринимательских инициатив в каждом конкретном случае должна обосновываться при помощи бизнес-плана. Немаловажным требованием является контроль и поддержка (в первую очередь, при помощи нефинансовых мер) предпринимателей на протяжении как минимум года после начала проекта. Это позволит выявить наиболее важные факторы, обусловившие успех (и неудачи) начинающих предпринимателей. Полученные данные можно использовать при оценке перспективности бизнес-планов и построении «профиля идеального предпринимателя», что, в свою очередь, повысит эффективность отбора наиболее перспективных идей и соискателей.

Не стоит забывать и о необходимости мер по государственной поддержке стартапов, позволяющих повысить долю инновационных продуктов и, соответственно, конкурентоспособность национальной экономике на мировом рынке.

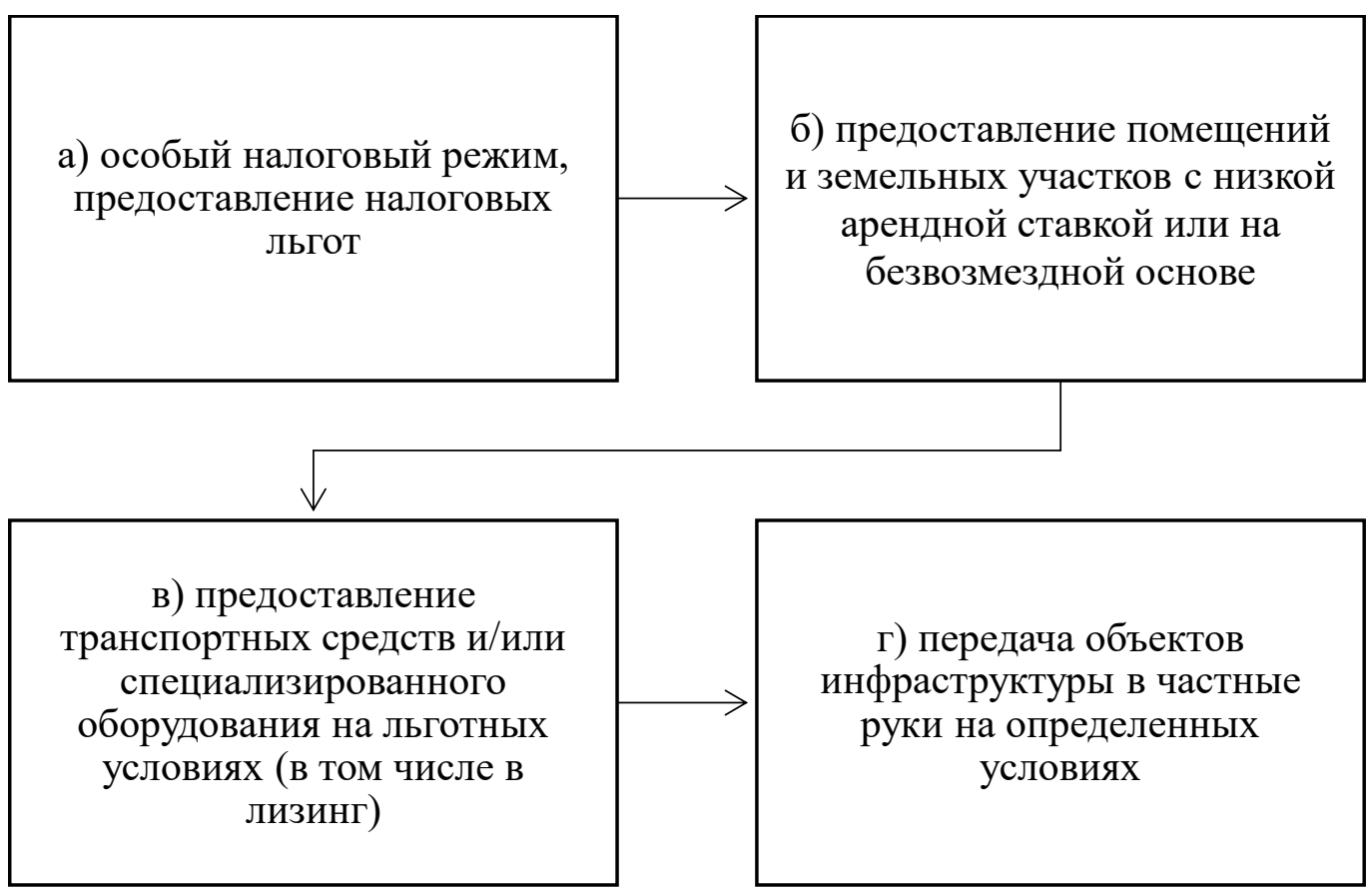

Рисунок 4. Меры поддержки инициатив населения со стороны государства в проекте ГЧП 


\section{Библиографический список}

1. Базжина В.А., Цыганкова И.В., Никитина О.Ю. Развитие нестандартных форм занятости в современной России // Российское предпринимательство. - 2014. - № 24. - С. 71-86.

2. Виленский А.В., Лылова О.В.Поиск стратегии социального развития регионов РФ // Экономика: вчера, сегодня, завтра. 2017. Т. 7. № 1А. С. 153-167

3. Дашкова Е.С., Дорохова Н. В. Занятость населения в России: современные тенденции: монография.- Воронеж: Воронежский ЦНТИ - филиал ФГБУ «РЭА» Минэнерго России, 2013. - 88 с],

4. Кройтор С. Новые модели бизнеса и нетрадиционные формы занятости в условиях цифровой трансформации: взгляд социолога // Общество и экономика.- 2019.- № 3.- С. 136-154.- doi: 10.31857/ S020736760004295-3.

5. Мерзлов И. Ю. Подходы к структурированию проектов государственно-частного партнерства // Journal of Economic Regulation.-2014.- № 1.- Том 5.- С. 77-87.- С. 83.

6. Румянцева Е. Е. Новая экономическая энциклопедия / Е. Е. Румянцева.-М.: ИНФРА-М, -2008.

7. Ускова Т.В., Копасова С. С. Диверсификация экономики региона -важнейшее условие повышения ее конкурентоспособности / Т. В. Ускова, С. С. Копасова // Экономические и социальные перемены в регионе: факты, тенденции, прогноз. -Вып. 40. -Вологда: ВНКЦ ЦЭМИ РАН. -2007.

8. Bonoli G. Adapting employment policies to post-industrial labour market risks. - IDHEAP, 2006. - № . 6/2006.

9. Degryse C. Digitalisation of the economy and its impact on labour markets. WorkingPaper. [Электронный ресурс]. URL: http://ssrn.com/abstract=2730550.

10. Glinka, B., Gudkova, S. Przedsiębiorczość. / Warszawa: Wydawnictwo Wolters Kluwer.-2011.-155 pp.-P. 65 .

11. Jaźwiński, I.Pomoc publiczna dla przedsiębiorstw. / Zeszyty Naukowe Uniwersytetu Szczecińskiego, Ekonomiczne Szczecin: Wydawnictwo Naukowe Uniwersytetu Szczecińskiego._-2007._ 453 pp.-. P. 88.

12. Kogut-Jaworska, M. Wsparcie przedsiębiorczości w ramach systemu pomocy publicznej w Polsce // Ekonomiczne Problemy Usług, - 2016. - № 125.-Pp. 213-224.- P. 219.

13. Siegel P.B., Johnson T. J., Alwang J. Regional economic diversity and diversification // Growth and change. 1995. Vol. 26. P. 262.

14. Sheldon G. Foreign labor employment in Switzerland: Less is not more //Schweizerische Zeitschrift für Politikwissenschaft. - 2001.- T. 7.- № . 1.- C. 104-112.

15. Stephen R. Barley, Beth A. Bechky, Frances J. Milliken. The changing nature of work: careers, identities, and work lives in the 21st century // Academy of Management Discoveries. - 2017. - № 2.- p. 111-115. - doi: 10.5465/ amd.2017.0034.

16. Taylor M. Good Work: The Taylor Review of Modern Working Practices, July 2017, 116 p. 